\title{
MONISMO ANÔMALO: UMA RECONSTRUÇÃO E REVISÃO DA LITERATURA
}

\author{
MARCELO FischBORN
}

\begin{abstract}
This paper reconstructs Donald Davidson's (1970) arguments for his theory of anomalous monism, and reviews the main criticisms it received. That theory is widely rejected nowadays, and given the numerous criticisms it received, it is reasonable to conclude that any rehabilitation attempt has a long way ahead. The diversity of those criticisms suggests that there is no consensus on exactly why anomalous monism fails, although difficulties seem to concentrate on the justification and possibility of the monist thesis, and not on the thesis of mental anomalism.
\end{abstract}

Keywords: Anomalous monism; Donald Davidson; mental events; physical events.

\section{Introdução}

O monismo anômalo é uma teoria em filosofia da mente defendida por Donald Davidson (1970). Essa teoria é monista porque diz que eventos mentais são eventos físicos; mas esse monismo é anômalo porque defende que (diferentemente do que aconteceria no domínio físico) não há leis estritas que permitam prever eventos mentais, ou reduzir teorias psicológicas a teorias físicas. ${ }^{1}$ Davidson considera um evento mental se, e somente se, pode ser corretamente descrito em termos mentais, e físico se, e somente se, pode ser corretamente descrito em termos físicos (1970, p.210-11). Descrições mentais são aquelas que incluem termos expressando atitudes proposicionais ('acreditar', 'querer', 'duvidar' etc.) e que criam contextos intensionais. ${ }^{2}$ A tese monista, portanto, diz que eventos que têm descrições mentais têm também descrições físicas; a anomalia do mental restringe o tipo de conexão que pode haver entre os vocabulários físico e mental.

Este artigo apresenta a estrutura argumentativa do monismo anômalo e alguns de seus pressupostos, e revisa de modo panorâmico as principais críticas que lhe foram dirigidas. A Seção 1 apresenta a ontologia de eventos pressuposta no argumento para a tese monista, que é apresentado na Seção 2. Como veremos, essa ontologia de eventos apresenta como possível que eventos mentais tenham também descrições físicas, e o argumento para o monismo busca mostrar que, além de possivelmente, evento mentais têm descrições físicas de fato. A Seção 3, por sua vez, apresenta os argumentos para as teses da anomalia e irredutibilidade do vocabulário mental, e a Seção 4 apresenta algumas das principais críticas dirigidas ao monismo anômalo, sugerindo uma visão sobre o estado atual dessa teoria na literatura.

Principia 18(1): 53-66 (2014).

Published by NEL — Epistemology and Logic Research Group, Federal University of Santa Catarina (UFSC), Brazil. 


\section{A ontologia de eventos como particulares}

Seguindo a linguagem coloquial, poderíamos dizer que uma frase como "João notou que seu cachorro não estava em casa" fala de um evento mental. Mas como isso pode ser, dado que, como Davidson (2001, p.xvii) aponta, a frase não contém, aparentemente, nenhuma expressão linguística funcionando como uma descrição de, ou mesmo se referindo a, um evento? Garantir essa possibilidade é crucial para o monismo anômalo, pois, como indicamos acima, Davidson define o que é ser um evento mental ou físico a partir das descrições que podem ter.

Para avançar nessa questão, Davidson (1967b) buscou investigar a forma lógica de frases sobre ações e eventos, e propôs que contêm uma quantificação implícita sobre eventos. A justificação para essa tese é que ela permite esclarecer certas relações inferenciais entre frases sobre ações que apresentam a chamada poliadicidade variável (Davidson 1967b, p.107-8). Consideremos o seguinte exemplo, fornecido pelo próprio Davidson:

1 Jones passou manteiga no pão, no banheiro, com uma faca, à meia-noite

Ao que parece, (1) implica outras frases, como:

2 Jones passou manteiga no pão

3 Jones passou manteiga no pão, no banheiro

Uma maneira de analisar (1), que não explica como essas inferências são possíveis, consiste em dizer que contém um predicado quinário do tipo 'Passar manteiga (autor, alvo, local, meio, tempo)'. Seguindo essa alternativa, teríamos que conceber (2) como contendo um predicado binário e (3) como contendo um predicado ternário. Assim, (2) teria a forma 'Passar manteiga (autor, alvo)', e (3) 'Passar manteiga (autor, alvo, local)'. O problema com essa sugestão é que predicados de diferentes aridades são, na verdade, predicados diferentes. Como consequência, não ficaria claro como, digamos, 'Passar manteiga 1 (Jones, pão, banheiro, faca, meia-noite)' implicaria 'Pas-

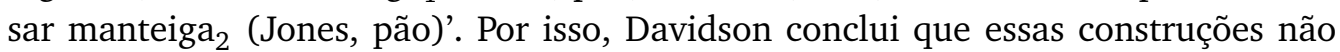
apresentam corretamente a forma lógica de (1), (2) e (3).

Como alternativa, Davidson propõe que se analise (1) como contendo uma quantificação sobre eventos, como a seguir:

1' $\exists x$ (Passar manteiga (Jones, no pão, $x$ ) \& No banheiro $(x)$ \& Com uma faca $(x)$ \& À meia-noite $(x))$

(1') quantifica sobre a variável para eventos, $x$, e consiste numa conjunção de predicações sobre essa variável. De maneira similar, analisaríamos (2) e (3) como:

2' $\exists x$ (Passar manteiga (Jones, no pão, $x$ ))

Principia 18(1): 53-66 (2014). 
3’ $\exists x$ (Passar manteiga (Jones, no pão, $x$ ) \& No banheiro $(x)$ )

Dessa maneira, propõe Davidson, fica fácil ver como (1) implica (2) e (3). A inferência de (2') ou de (3') a partir de (1') é válida porque instancia a regra mais geral da eliminação de conjunções (ver Davidson 1967b, p.119; ver também a reconstrução de Glüer 2011, p.173-4).

Essa análise da forma lógica fornece uma pista inicial de como poderíamos dar sentido à possibilidade, exigida pela tese monista, de um mesmo evento ter diferentes descrições (digamos, uma mental e uma física). Para entender qual é essa pista, podemos considerar as duas frases a seguir que, seguindo o modelo recém considerado, forneceriam, respectivamente, a forma lógica de "Jones decidiu ir de ônibus" e "Uma atividade elétrica de $4 \mu \mathrm{V}$ aconteceu na região R":

$4 \exists x$ (Decisão (Jones, ir de ônibus, $x$ ))

$5 \exists x$ (Atividade elétrica $(x) \& 4 \mu \mathrm{V}(x) \& \operatorname{Em~R}(x)$ )

Por instanciação do existencial (na lógica clássica de predicados), podemos inferir:

6 Decisão (Jones, ir de ônibus, a) [4, instanciação do existencial]

7 Atividade elétrica (b) \& $4 \mu \mathrm{V}$ (b) \& Em R (b) [5, instanciação do existencial]

Dadas (6) e (7), poderíamos agora simplesmente colocar a questão: $a=b$ ? Em outras palavras, estaríamos perguntando se um evento descrito como "Jones decidiu ir de ônibus" é idêntico a um evento descrito como "Uma atividade elétrica de $4 \mu \mathrm{V}$ aconteceu na região $\mathrm{R}$ ".

Quais seriam as condições de verdade ou falsidade de enunciados de identidade sobre eventos? Davidson aceita que, para postular eventos como uma categoria ontológica própria, é necessário fornecer um critério adequado sobre a identidade de eventos - "Nenhuma entidade sem identidade", na expressão de Quine (ver Davidson 1969, p.164). Em sua primeira tentativa de fornecer tal critério, Davidson sugeriu que "eventos são idênticos se e somente se têm exatamente as mesmas causas e efeitos" (1969, p.179). Uma crítica decisiva a esse critério foi apresentada por Quine (1985, p.166) que argumentou ser circular "individuar eventos quantificando sobre os próprios eventos". Isso porque causas e efeitos são também eventos e, dessa maneira, o critério diria que eventos são idênticos se, e somente se, são causas e efeitos exatamente dos mesmos eventos. Em resposta, Davidson aceitou a crítica e a proposta de Quine. Nessa proposta, eventos são considerados idênticos se, e somente se, "ocupam os mesmos lugares nos mesmos instantes" (Davidson 1985, p.309). Isso equivale a dizer que eventos são incorporados à categoria de objetos físicos, distinguindo-se destes não em gênero, mas apenas em grau (ver Quine 1985, p.167; 1986, p.30).

Principia 18(1): 53-66 (2014). 
Como veremos mais adiante (Seção 4), também o critério quineano de identidade de eventos recebeu críticas. E, como já vimos, uma função essencial da ontologia de eventos no monismo anômalo é apresentá-los como particulares que podem ser variadamente descritos. Essa possibilidade é uma condição necessária para a tese monista, e é pressuposta no argumento apresentado a seguir. Sendo assim, problemas na ontologia de eventos como particulares serão também problemas para o monismo anômalo como um todo.

\section{2. $\mathrm{O}$ argumento para $\mathrm{o}$ monismo}

De acordo com a reconstrução mais usual, e que foi induzida pelo próprio Davidson, o argumento em favor da tese monista compõe-se de três premissas (citadas de Davidson 1970, p.208):

P1. Interação causal: "ao menos alguns eventos mentais interagem causalmente com eventos físicos".

P2. Caráter nomológico da causalidade: "eventos relacionados como causa e efeito caem sob leis deterministas estritas".

P3. Anomalia do mental: "não há leis deterministas estritas com base nas quais eventos mentais possam ser previstos e explicados". 3

Dado o critério anteriormente apresentado do que conta como um evento mental ou físico, a primeira premissa diz que há eventos que têm descrição mental que interagem com eventos que têm descrição física. A segunda premissa introduz a noção de uma 'lei estrita', que tem como uma de suas condições necessárias que a lei em questão não contenha cláusulas ceteris paribus, isto é, cláusulas do tipo "sendo tudo o mais igual" que permitam exceções (ver Davidson 1970, p.219; 1993, p.8-9; 1995, p.266). A terceira premissa, por sua vez, nega que haja leis desse tipo formuladas em termos mentais.

Com essas premissas, Davidson oferece o seguinte raciocínio para derivar a tese monista:

Suponha que $m$, um evento mental, causou $p$, um evento físico [por P1]; então, sob alguma descrição $m$ e $p$ instanciam uma lei estrita [por P2]. Essa lei só pode ser física, de acordo com o último parágrafo [no qual P3 é defendida]. Mas se $m$ cai sob uma lei física, ele tem uma descrição física. O que equivale a dizer que é um evento físico [monismo]. (1970, p.224)

Como podemos ver, esse raciocínio recorre à possibilidade de um único evento ter simultaneamente uma descrição mental e uma descrição física, apontada anteriormente (Seção 1). Quando um evento com descrição mental causa ou é causado por

Principia 18(1): 53-66 (2014). 
um evento físico (por P1), ${ }^{4}$ esse evento tem de ter uma descrição que figure numa lei causal estrita (por P2). Mas (P3) diz que não há leis desse tipo formuladas em termos mentais e, por isso, o evento com descrição mental tem de ter também uma descrição diferente, não-mental, que figure numa lei causal estrita.

Como alcançar a conclusão de que a descrição não-mental em questão é física? Como alguns autores notaram, Davidson precisa (e parece recorrer a) uma premissa adicional (ver Davidson 1970, p.219, 223-4; 1993, p.8; Johnston 1985, p.411; Antony 2003, p.3-4). Acompanhando Johnston, Antony (2003, p.4) propõe uma quarta premissa:

P4. "Há leis estritas apenas na física."

Com o auxílio dessa nova premissa, poderíamos concluir que eventos mentais que interagem causalmente com eventos físicos têm descrições que figuram numa lei estrita física, sendo, consequentemente, eventos físicos. Esse é, portanto, o argumento de Davidson em favor do monismo, que é dito anômalo por negar explicitamente a possibilidade de leis envolvendo termos mentais em uma de suas premissas. ${ }^{5} \mathrm{Na}$ Seção 4, veremos algumas das críticas que esse argumento recebeu.

\section{O argumento para a anomalia e irredutibilidade do mental}

Antes de considerar os argumentos que Davidson oferece em favor da anomalia do mental (P3), será conveniente tornar preciso o que essa tese nega. Podemos fazer isso considerando uma versão simplificada do modelo de explicação e predição de eventos a partir de leis estritas que Davidson ofereceu (1967a, p. 158). Nesse modelo, a ocorrência da causa ou do efeito pode ser inferida da conjunção de uma lei causal estrita com um enunciado que diz que o efeito ou a causa ocorreu.

Uma lei estrita em sua forma mais completa - uma lei causal "de pleno direito", como Davidson a chama - tem a forma de uma conjunção:

$\mathrm{L} \forall e(P e \rightarrow \exists ! f(Q f \& C e f)) \& \forall e(Q e \rightarrow \exists ! f(P f \& C f e))^{6}$

A primeira parte de (L), isto é, o lado esquerdo da conjunção, diz que, para qualquer evento $e$, se $e$ é $P$, então existe um segundo e único evento, $f$, que é $Q$, tal que $e$ causa $f$. A segunda parte diz algo parecido, mas afirma que a ocorrência de um evento de tipo $Q$ implica que houve um evento de tipo $P$ que o causou. Em suma, (L) diz que eventos de tipo $P$ e $Q$ estão sempre relacionados como causa e efeito, respectivamente.

Suponhamos, então, que tenha ocorrido um evento, $a$, de tipo $P$ :

E1. $P a$

Principia 18(1): 53-66 (2014). 
Dados os enunciados (L) e (E1), poderíamos inferir a ocorrência de um segundo evento, de tipo $Q$, e que é efeito de $a$ :

\section{E2. $Q b \& C a b$}

Com base nesse modelo, poderíamos dizer que os eventos $a$ e $b$, sob as descrições ' $\mathrm{P}$ ' e 'Q', são abrangidos pela lei estrita (L). Embora Davidson (1967a, p. 159) conceda formas menos exigentes de explicação ou predição de eventos, (P2) implica que todo evento que se relaciona causalmente com outros tem alguma descrição que figura numa lei estrita como (L).

Como vimos, a função da tese da anomalia do mental (P3) no argumento para o monismo é precisamente negar que eventos mentais que interagem causalmente com eventos físicos sejam abrangidos por leis estritas sob descrições mentais. Sendo assim, (P3) precisa negar, em primeiro lugar, que predicados mentais possam ocupar tanto a posição de 'P' como de 'Q' em leis como (L). Em segundo lugar, Davidson também nega, com base em (P1), que possa haver leis estritas puramente psicológicas, dada a restrição, já mencionada, a eventos mentais que interagem causalmente com eventos físicos, supostamente não-mentais (1970, p.224, ver também Yalowitz 2012, seção 2.3). Assim, a tese da anomalia do mental nega a possibilidade de qualquer tipo de participação de predicados mentais em leis causais estritas como (L) - seja em leis mistas, com predicados mentais e físicos, por exemplo, ou em leis puramente psicológicas.

Por fim, a tese da anomalia do mental nega um terceiro tipo de lei, que Davidson chama de 'leis psicofísicas' e que correspondem ao que se costuma chamar de 'leis ponte' (bridge laws). Leis desse tipo não visam relacionar diferentes eventos causalmente, mas mostrar que dois predicados são coextensivos, isto é, valem de todos e apenas dos mesmos eventos. Elas têm a seguinte forma:

$$
\text { P. } \forall e(F e \longleftrightarrow M e)
$$

Entendendo-se ' $\mathrm{F}$ ' como um predicado físico e ' $\mathrm{M}$ ' como um predicado mental, (P) diria que ' $\mathrm{F}$ ' é verdadeiro de todos e apenas os eventos dos quais ' $\mathrm{M}$ ' é verdadeiro. Esse é, assim, o terceiro tipo de lei estrita envolvendo predicados mentais que a tese da anomalia do mental nega. ${ }^{7}$

Qual é, então, o argumento para a tese da anomalia do mental? Como Davidson (1970, p.209) diz, a segunda parte de seu artigo "argumenta que não pode haver leis psicofísicas estritas". Ele reconhece que "isso não é bem o princípio da anomalia do mental, mas sob suposições razoáveis o implica” (p.209). A argumentação para a anomalia do mental, assim, concentra-se em negar leis psicofísicas como (P), mas Davidson pensa que pode ser estendida para negar que leis estritas como (L) possam envolver predicados mentais. De acordo com aquela que parece a leitura mais 
recorrente desse argumento, não poderia haver leis psicofísicas estritas porque o uso de predicados físicos e mentais é regido por princípios constitutivos diferentes. ${ }^{8} \mathrm{O}$ uso dos predicados mentais, em particular, seria regido por princípios de racionalidade, que não estariam presentes no caso de predicados físicos:

Não há leis psicofísicas estritas devido aos diferentes compromissos dos esquemas mental e físico. É uma característica da realidade física que uma mudança física pode ser explicada por leis que a conectam com outras mudanças e condições fisicamente descritas. É uma característica do mental que a atribuição de fenômenos mentais tem de ser sensível ao pano de fundo de razões, crenças e intenções do indivíduo. Não pode haver conexões estreitas entre os domínios se for para cada um permanecer fiel à sua própria fonte de evidência. [...] [Q] uando usamos os conceitos de crença, desejo e demais, temos de estar preparados, conforme a evidência se acumula, para ajustar nossa teoria à luz de considerações de cogência global: o ideal constitutivo de racionalidade controla parcialmente cada fase na evolução do que tem de ser uma teoria em desenvolvimento. (Davidson 1970, p.222-3)

Alguns traços gerais desse argumento são claros. Primeiramente, trata-se de um raciocínio de tipo a priori, que, ao apontar certas características sobre a natureza de dois vocabulários (mental e físico), conclui que não pode haver conexões estritas entre ambos. Em segundo lugar, as características apontadas dizem que o emprego de cada um dos vocabulários é regido por princípios diferentes: a atribuição de atitudes proposicionais respeita princípios gerais de racionalidade e coerência com o pano de fundo de outras atitudes proposicionais da pessoa; e o emprego de descrições físicas seria regulado por referência a um pano de fundo de leis e outras condições físicas. ${ }^{9}$ Por fim, Davidson pretende inferir dessas considerações que, se os diferentes princípios forem respeitados, não há como predicados dos dois domínios terem conexões estritas.

Apesar desses traços gerais do argumento parecerem claros, não é fácil ver como poderia se seguir a conclusão de que não há (ou não pode haver) conexões estritas entre quaisquer dois predicados, um mental e um físico. Em vez de uma elaboração mais técnica, gostaria de oferecer uma analogia que talvez ajude a esclarecer o espírito da sugestão de Davidson. Nessa analogia, predicados mentais e físicos são análogos de duas peças em um jogo de tabuleiro. Os eventos dos quais esses predicados podem ser verdadeiros ou falsos seriam as casas do tabuleiro, sendo o análogo de um predicado ser verdadeiro de um evento o fato de uma peça parar sobre uma casa. Dada a tese monista, é possível que as duas peças parem eventualmente sobre uma mesma casa. O análogo dos diferentes princípios regendo o uso de cada predicado seria o fato de que diferentes arremessos de dado regem o movimento de cada peça. Se essa analogia é apropriada, uma lei psicofísica como (P) seria altamente improvável, pois é altamente improvável que, em uma partida, as duas peças parem

Principia 18(1): 53-66 (2014). 
apenas e exatamente nas mesmas casas. ${ }^{10}$

Essa a analogia pode ser também adaptada para excluir leis estritas como (L), conectando causalmente um predicado mental e um predicado físico. (L) diz que os eventos dos quais são verdadeiros os predicados 'P' e 'Q' estão sempre relacionados como causa e efeito. Poderíamos associar a relação de causa e efeito, no tabuleiro, à sucessão de duas casas. Para haver uma lei como (L) relacionando um predicado mental e um predicado físico, teria de ser o caso que ambas as peças caíssem sempre e apenas em casas sucessivas. Mas como um lance de dado diferente é feito para cada peça - para cada predicado - é novamente altamente improvável que isso aconteça. Se essas analogias fazem alguma justiça ao argumento de Davidson, o que sugerem é que, dados os princípios diferentes regendo predicados mentais e predicados físicos, não haveria nenhuma razão positiva para esperar que mantenham conexões como as afirmadas por (L) e (P). Conexões como essas só seriam obtidas por obra de um acaso com poucas chances de se concretizar.

Com essas sugestões (que obviamente não a justificam definitivamente) Davidson adota a tese da anomalia do mental em sentido pleno: nega leis estritas puramente psicológicas com base na premissa da interação causal (P1), e nega leis estritas como (L) e (P) com base nas considerações sobre os diferentes princípios regendo o emprego dos vocabulários mental e físico. Uma tese adicional, que se segue dessa adoção irrestrita da tese da anomalia do mental, é que o vocabulário mental - ou enunciados gerais envolvendo predicados mentais - é irredutível a um vocabulário puramente físico. Nas palavras de Davidson, "o mental é nomologicamente irredutível" (1970, p.216). Isso porque leis psicofísicas como (P) são tradicionalmente vistas como uma condição necessária para a redução de enunciados de uma teoria a enunciados de outra - por exemplo, para a redução dos enunciados da psicologia a enunciados da física (ver, por exemplo, Fodor 1974, p.98). Assim, (P3) representa a tese da anomalia do mental e acarreta, ainda, a tese da irredutibilidade do vocabulário mental ao vocabulário físico.

Por fim, vale mencionar algumas considerações sobre a tese da superveniência das características (ou descrições) mentais sobre as características físicas de eventos, que Davidson apresentou no contexto de sua defesa do monismo anômalo. Ele disse:

Embora a posição que descrevo negue que haja leis psicofísicas, ela é compatível com a concepção de que as características mentais são, em algum sentido, dependentes de, ou supervenientes sobre características físicas. Essa superveniência poderia ser entendida como dizendo que não pode haver dois eventos semelhantes em todos os aspectos físicos mas diferindo em algum aspecto mental, ou que um objeto não pode se alterar em algum aspecto mental sem alterar-se em algum aspecto físico. (Davidson 1970, p.214) ${ }^{11}$

Assim, essa tese introduziria restrições sobre a relação entre as descrições mentais e Principia 18(1): 53-66 (2014). 
físicas que podem se aplicar a eventos particulares, embora essas restrições não fossem tão fortes, segundo Davidson, para acarretar leis estritas envolvendo descrições de ambos os tipos, nem redutibilidade (ver 1970, p.141; 1993, p.7).

\section{Recepção crítica e estado da arte}

O monismo anômalo tem recebido inúmeras críticas desde a década de 1970. Dentre essas objeções, talvez a que teve maior repercussão foi a objeção de epifenomenismo. Segundo essa objeção, as premissas adotadas por Davidson (particularmente P2, P3 e P4) implicariam uma tese conhecida como epifenomenismo de propriedades, que diz que as propriedades mentais dos eventos são causalmente inertes (os principais proponentes dessa crítica são Honderich 1982; Kim 1989, 1993; McLaughlin 1993; e Sosa 1993). Como resposta, Davidson e vários outros responderam que o monismo anômalo não se compromete com a tese de que relações causais acontecem em virtude de quaisquer propriedades (sejam físicas, mentais ou de qualquer tipo), e que Davidson sequer conceberia propriedades em algum sentido ontologicamente sério (ver Melchert 1986; Davidson 1993; Crane 1995; Campbell 2003; Gibb 2006; Heil 2008). Alternativamente, outros autores questionam a suposição de que o epifenomenismo de propriedades é falso, e que seria necessariamente uma consequência indesejável de qualquer teoria da mente (ver Horowitz 1999 e Robinson 2012). Segundo esses autores, as razões costumeiramente oferecidas contra o epifenomenismo de propriedades são todas respondíveis, de modo que sua rejeição careceria de uma justificação adequada.

Nesse contexto, discutiu-se como a tese da superveniência poderia se acomodar no interior do monismo anômalo. Objetou-se, por exemplo, que a tese não é compatível com o monismo anômalo, particularmente com a tese da anomalia do mental (ver Kim 1989, p.35; Evnine 1991, p.68-9, por exemplo). Davidson (1993) respondeu a essas críticas (p. 7) e, além disso, valeu-se da tese da superveniência para defender que o mental "faz diferença" no monismo anômalo (p.14). Para seus críticos, no entanto, ambos os esforços não foram bem sucedidos (ver Kim 1993; McLaughlin 1993; Sosa 1993). O caráter e o lugar da tese da superveniência no interior do monismo anômalo parecem, assim, permanecerem em aberto (ver Yalowitz 2012, sec. 5.3).

Quanto às premissas no argumento para o monismo, apenas o princípio da interação causal (P1) não tem sido questionado contemporaneamente. ${ }^{12}$ Na verdade, uma busca por uma explicação de como a interação mente-corpo acontece (pressupondo, portanto, que de fato acontece) tem estado na agenda filosófica pelo menos desde as críticas da Princesa Elisabeth ao dualismo de Descartes. ${ }^{13}$ Para ser preciso, mesmo uma posição epifenomenista poderia aceitar P1, já que aceita que eventos

Principia 18(1): 53-66 (2014). 
mentais são efeitos (embora não causas) de eventos físicos (ver Lycan 2009, p.557, n. 19).

A premissa (P2), por sua vez, que diz que enunciados causais singulares implicam a existência de leis estritas, tem atraído algumas críticas (por exemplo, Burge 1983, p.610, 1993, p.112; e Fodor 1990, p.153-4). Inicialmente, Davidson fez dela apenas uma suposição, e só posteriormente argumentou em seu favor (Davidson 1995). Esses argumentos posteriores foram até agora pouco discutidos. De um modo mais geral, há autores que endossam uma concepção de causalidade como dependente de leis (por exemplo, Armstrong 1997, capítulo 14), mas o que parece predominar no assunto é a falta de consenso (ver Schaffer 2008).

Quanto à tese da anomalia do mental (P3), os argumentos que Davidson ofereceu em seu favor foram considerados pouco claros por alguns (ver discussões e interpretações em McLaughlin 1985; Kim 1985; Yalowitz 1997, 2012, sec. 4). Independentemente desses argumentos, no entanto, não parece haver casos conhecidos de leis psicológicas estritas que poderiam servir como contraexemplos à tese. Na verdade - e isto constitui uma crítica à quarta premissa (P4) - tem-se questionado que mesmo na física, geralmente considerada o paradigma de precisão na ciência, haja leis causais estritas tais como entendidas por Davidson (ver Cartwright 1983; e Harbecke 2013, por exemplo).

Uma dificuldade ainda mais básica tem sido apontada a respeito da ontologia de eventos pressuposta pelo monismo de Davidson. Davidson precisa fornecer um critério satisfatório para a identidade de eventos, mas, segundo alguns, não foi capaz de fazê-lo. Como vimos acima, o critério proposto inicialmente (Davidson 1969) de que eventos são idênticos se, e somente se, têm exatamente as mesmas causas e efeitos - foi rejeitado após a crítica de circularidade feita por Quine (1985). Davidson (1985) adotou então a estratégia quineana de assimilar eventos à categoria de objetos físicos, considerados idênticos se, e somente se, têm a mesma localização espaço-temporal (ver, por exemplo, Quine 1985, p. 167; 1986, p.30). O problema com isso, segundo alguns, é que o próprio Davidson teria oferecido um contraexemplo, a saber, a possibilidade de uma bola de metal aquecer-se e girar 35 graus simultaneamente. Isso indicaria - contra o critério de identidade em questão - que mais de um evento pode ocorrer em um mesmo lugar ao mesmo tempo (ver Lombard 1998, p.283), e seria um problema básico para o monismo anômalo (ver Schneider 2013, p.148-9; 2012, p.720, n. 3; e também Latham 2003 e Marcus 2006).

\section{Conclusão}

Este artigo apresentou as principais teses e argumentos que compõem o monismo anômalo de Davidson, e ofereceu ainda um panorama geral das discussões e críticas 
que recebeu. Parece razoável concluir que qualquer tentativa futura de reabilitação do monismo anômalo teria um longo trabalho pela frente. De fato, a maior parte dos autores dedicados atualmente à filosofia da mente rejeita o monismo anômalo. Apesar disso, as razões oferecidas para sua rejeição têm sido diversificadas e nem sempre consensuais. A objeção de epifenomenismo, por exemplo, uma das mais difundidas na literatura, já teve um número equiparável de defensores e críticos. Entre as objeções alternativas, não parece que alguma tenha se sobressaído de maneira decisiva sobre as demais, e parece que as teses da anomalia e irredutibilidade do mental permanecem ainda defensáveis. Isso sugere que, embora ainda não se tenha delimitado de maneira suficientemente precisa as razões para se rejeitar o monismo anômalo, as dificuldades maiores tendem a convergir sobre a defesa, e possibilidade, da tese monista, e não sobre a tese da anomalia do mental. ${ }^{14}$

\section{Referências}

Antony, M. 2003. Davidson's argument for monism. Synthese 135: 1-12.

Armstrong, D. 1997. A world of states of affairs. Cambridge: Cambridge University Press. Burge, T. 1983. Essays on Actions and Events, by Donald Davidson. Ethics 93(3): 608-11.

_ 1993. Mind-body causation and explanatory practice. In: J. Heil; A. Mele, 1993, p.97-120.

Campbell, N. 2003. Causes and causal explanations: Davidson and his critics. Philosophia 31: 149-57.

Cartwright, N. 1983. How the laws of physics lie. Oxford: Oxford University Press.

Crane, T. 1995. The mental causation debate. Proceedings of the Aristotelian Society 69: 21136.

Davidson, D. 1963. Actions, reasons, and causes. In: D. Davidson (2001), p.3-19. Disponível em português em Davidson (2012).

- 1967a. Causal relations. In: D. Davidson (2001), p.149-62.

- 1967b. The logical form of action sentences. In: D. Davidson (2001), p.105-48.

- 1969. The individuation of events. In: D. Davidson (2001), p.163-80.

- 1970. Mental events. In: D. Davidson (2001), p.207-25.

- 1985. Reply to Quine on events. In: D. Davidson (2001), p.305-11.

- 1993. Thinking causes. In: J. Heil; A. Mele (1993), p.3-17.

- 1995. Laws and cause. Dialectica 49(2-4): 263-79.

- 2001. Essays on actions and events. 2nd ed. Oxford: Clarendom Press.

- 2012. Ações, razões e causas. Tradução de Marcelo Fischborn. Crítica. Disponível em: http://criticanarede.com/accoes.html. Acesso em 10 dez. 2013.

Descartes, R.; Elisabeth, P. 2007. The correspondence between Princess Elisabeth of Bohemia and René Descartes. Ed. and Transl. by L. Shapiro. Chicago: The University of Chicago Press.

— 2013. Correspondências de 1643 entre Descartes e Elisabeth. Tradução de Marcelo Fischborn. Inquietude 4(1): 171-86.

Evnine, S. 1991. Donald Davidson. Stanford: Stanford University Press.

Principia 18(1): 53-66 (2014). 
Fodor, J. 1974. Special sciences, or the disunity of science as a working hypothesis. Synthese 28: $97-115$.

-1990. Psychosemantics: The problem of meaning in the philosophy of mind. Cambridge, Mass.: MIT Press.

Gibb, S. 2006. Why Davidson is not a property epiphenomenalist. International Journal of Philosophical Studies 14: 407-22.

Glüer, K. 2011. Donald Davidson: A short introduction. Oxford: Oxford University Press.

Harbecke, J. 2013. On the distinction between law schemata and causal laws. Acta Analytica [On-line]: 1-12.

Heil, J. 2008. Anomalous monism. In: H. Dyke (ed.) From truth to reality: New essays in metaphysics, London: Routledge, p.85-98.

Heil, J.; Mele, A. (eds.) 1993. Mental causation. Oxford: Clarendon Press.

Honderich, T. 1982. The argument for anomalous monism. Analysis 42: 59-64.

Horowitz, H. 1999. Is there a problem in physicalist epiphenomenalism?. Philosophy and Phenomenological Research 59(2): 421-34.

Johnston, M. 1985. Why having a mind matters. In: E. Lepore; B. McLaughlin (1985), p.40826.

Kim, J. 1985. Psychophysical laws. In: Lepore; McLaughlin (1985), p.369-86.

1993. Can supervenience and 'non-strict laws' save anomalous monism?. In: J. Heil; A. Mele (1993), p.19-26.

. 1989. The myth of non-reductive materialism. Proceedings and Addresses of the American Philosophical Association 63: 31-47.

Latham, N. 2003. What is token physicalism?. Pacific Philosophical Quarterly 84(3): 270-90.

Lepore, E.; McLaughlin, B. (eds.) 1985. Actions and events: perspectives on the philosophy of Donald Davidson. Oxford: Basil Blackwell.

Lombard, L. 1998. Ontologies of events. In: C. Macdonald; S. Laurence (eds.) Contemporary readings in the foundations of metaphysics. Oxford: Blackwell.

Lycan, W. 2009. Giving dualism its due. Australasian Journal of Philosophy 87(4): 551-63.

McLaughlin, B. 1985. Anomalous monism and the irreducibility of the mental. In: E. Lepore;

B. McLaughlin (1985), p.331-68.

- 1993. On Davidson's response to the charge of epiphenomenalism. In: J. Heil; A. Mele (eds.) (1993), p.27-40.

Marcus, E. 2006. Events, sortals, and the mind-body problem. Synthese 150: 99-129.

Melchert, P. 1986. What's wrong with anomalous monism. Journal of Philosophy 83: 265-74.

Quine, W. 1986. Philosophy of logic, 2nd ed. Cambridge, Mass.: Harvard University Press.

. 1995. Events and reification. In: E. Lepore; B. McLaughlin (eds.) (1985), p.162-71.

Robinson, W. 2012. Epiphenomenalism. In: E. Zalta (ed.) The Stanford Encyclopedia of Philosophy (Summer 2012 Edition). Disponível em:

http://plato.stanford.edu/archives/sum2012/entries/epiphenomenalism/. Acesso em 5 dez. 2013.

Schaffer, J. 2008. The Metaphysics of Causation. The Stanford Encyclopedia of Philosophy (Fall 2008 Edition). Disponível em:

http://plato.stanford.edu/archives/fall2008/entries/causation-metaphysics/. Acesso em 28 nov. 2013.

Principia 18(1): 53-66 (2014). 
Schneider, S. 2012. Non-reductive physicalism cannot appeal to token identity. Philosophy and Phenomenological Research 85(3): 719-28.

. 2013. Non-reductive physicalism and the mind problem. Noûs 47(1): 135-53.

Sosa, E. 1993. Davidson's Thinking causes. In: J. Heil; A. Mele (eds.) (1993), p.41-50.

Yalowitz, S. 1997. Rationality and the argument for anomalous monism. Philosophical Studies 87(3): 235-58.

. 2012. Anomalous monism. In: E. Zalta (ed.), The Stanford Encyclopedia of Philosophy (Winter 2012 Edition). Disponível em:

http://plato.stanford.edu/archives/win2012/entries/anomalous-monism.

Acesso em 9 dez. 2013.

Marcelo Fischborn

Universidade Federal de Santa Maria

marcelo_fischborn@yahoo.com.br

Resumo. Este artigo reconstrói os argumentos de Donald Davidson (1970) em favor de sua teoria do monismo anômalo e revisa as principais críticas que recebeu. Essa teoria é amplamente rejeitada atualmente e, dadas as inúmeras críticas recebidas, é razoável concluir que qualquer tentativa de reabilitação tem um longo caminho pela frente. A diversidade dessas críticas sugere que não há consenso sobre por que exatamente o monismo anômalo fracassa, embora as dificuldades pareçam convergir sobre a justificação e possibilidade da tese monista, e não sobre a anomalia do mental.

Palavras-chave: Monismo anômalo; Donald Davidson; eventos mentais; eventos físicos.

\section{Notas}

${ }^{1}$ Os termos 'mental' e 'psicológico' são usados como equivalentes ao longo deste trabalho, conforme a definição de Davidson, apresentada na sequência.

${ }^{2}$ Por 'contexto intensional' Davidson refere-se a frases em que a substituição de termos coextensionais não garante a preservação da verdade. Por exemplo, do fato de que João acredita que está vendo a estrela da manhã não se segue que João acredite que esteja vendo a estrela da tarde (ainda que 'a estrela da manha' e 'a estrela da tarde' refiram-se ao mesmo objeto). Vale notar que Davidson restringe o âmbito do mental a eventos com conteúdo proposicional. Não fica claro, assim, que outros fenômenos caracteristicamente mentais sejam incluídos, como dores, ou estados qualitativos (ver, por exemplo, Melchert 1986, p.274; Antony 2003, p.2; em contraste com Davidson 1970, p.211).

${ }^{3}$ Davidson (1970, p.208, n. 3; 1995, p.266) afrouxa a exigência, em P2, de que as leis sejam 'deterministas', e faço o mesmo no que segue. O essencial para o argumento é que P3 negue que leis envolvendo termos mentais possam fornecer o tipo de leis que P2 exige para relações causais.

${ }^{4}$ A primeira premissa, assim, impõe uma segunda restrição sobre o escopo do argumento, isto é, ele fala apenas de eventos mentais que interagem causalmente com eventos físicos (ver Davidson 1970, p.208, 210; e Antony 2003, p.2).

Principia 18(1): 53-66 (2014). 
${ }^{5}$ Antony (2003, p.5) objeta que aceitar (P4) torna - contrariamente às pretensões originais de Davidson - a tese da anomalia do mental (P3) ociosa no argumento. Mas admite, ainda assim, que Davidson poderia simplesmente acrescentar a tese ao seu monismo para mantê-lo anômalo.

${ }^{6}$ Esta é uma versão ligeiramente simplificada da análise feita por Davidson (1967a, p.158). ${ }^{7}$ Davidson (1970, p.215) diz que não pode haver "uma frase física aberta 'Px' verdadeira de todos e apenas dos eventos que têm alguma propriedade mental" (p.215).

${ }^{8}$ Essa interpretação é endossada por McLaughlin (1985, p.353) e Glüer (2011, p.253), e parece ser a mais condizente com o texto de Davidson (1970). Yalowitz (2012, sec. 4) distingue dois outros argumentos possíveis. O primeiro poderia vir de um apelo à indeterminação da tradução, uma alternativa que Davidson sugere, mas não leva adiante (ver 1970, p.2223; ver também McLaughlin 1985, p.352; e Yalowitz 2012, sec. 4.1). O segundo argumento teria sido proposto em alguns textos posteriores, sugerindo que termos mentais difeririam de termos físicos por serem "definidos causalmente", isto é, por sua natureza ser em parte determinada pelas causas e efeitos que têm (ver Yalowitz 2012, sec. 4.3).

9 Sobre o aparente emprego, por Davidson, da tese do fechamento causal do âmbito físico na diferenciação dos vocabulários mental e físico, ver Antony (2003, p.4-5) e Yalowitz (2012, suplemento).

${ }^{10}$ Eis um dos aspectos em que a analogia sugerida pode não ser muito boa: a prática de arremessar o dado e movimentar a peça correspondente de acordo com o número obtido é qualitativamente igual quer se trate de uma peça (mental) ou outra (física), diferindo apenas por serem ocorrências distintas do arremesso do dado e possivelmente distintas por seu conteúdo, o número obtido. Alguém poderia insistir que a prática de empregar predicados mentais, por um lado, e físicos, por outro, não difere, para Davidson, apenas pelo conteúdo dos princípios, mas também qualitativamente. Deixo essa possibilidade em aberto aqui.

${ }^{11}$ Davidson (1993, p.4) acrescentou que o que pretendera dizer fora que "um predicado $\mathrm{p}$ é superveniente sobre um conjunto de predicados $\mathrm{S}$ se, e somente se, $\mathrm{p}$ não distingue quaisquer entidades que não podem ser distinguidas por $S$ ".

12 Davidson oferece uma defesa parcial desse princípio, ao argumentar que eventos mentais (razões) são causas (ver Davidson 1963).

${ }^{13}$ Ver as correspondências escritas por Elisabeth em 6 de maio, 10 de junho e 1o de julho de 1643 em Descartes e Elisabeth (2007), disponíveis em português em Descartes e Elisabeth (2013). Ver também Heil e Mele (1993, especialmente p. v).

${ }^{14}$ Agradeço aos professores Rogério Severo, Frank Sautter, Gilberto Gomes e Wilson Mendonça por comentários e sugestões a uma versão prévia deste artigo.

Principia 18(1): 53-66 (2014). 